\title{
Introduction
}

\section{Enrico Colombatto}

\section{On property rights and economic analysis}

The role of property rights in economics can hardly be overemphasised. Indeed, since all the essential controversies about the purpose and nature of economic science can be reformulated as debates on the features of individual behaviour (consumption, production, leisure, policy making), and since the motivation and opportunities for human action are defined by systems of property rights, it is fair to say that economic analysis is about the consequences of the assignment and use of property. Of course, economics still remains a question of scarcity, as individuals try to enhance their well-being in a world characterised by ignorance and limited resources. But the very concept of scarcity would make little sense unless the idea of property were taken into account, for property rights define the structure of incentives that lead agents to struggle, compete and also cooperate in order to satisfy their needs and ambitions. Indeed, property rights characterise scarcity itself, which becomes a meaningful concept only if the possibility of using - or benefiting from - a given good is related to how much one gains by transferring (acquiring) those rights to (from) others.

This view is now commonly accepted; even by those who favour technocratic approaches based on formal models where institutions hardly play a role. Contrary to common belief, however, the link between economic performance and property rights goes well beyond the standard problems of static optimisation, whereby supposedly efficient techniques are necessarily adopted and inputs fully employed (whatever these terms mean). In fact, the major impact of property rights economics concerns ethical and dynamic issues. This is actually the focus of the chapters presented in this volume, which examine the effects of property rights (or lack of) from three different viewpoints: ethics, incentives and efficiency. In turn, these elements justify the origin and contribute to moulding the dynamics of institutions following changes in ideology, in technology and in the rules of the game typical of the law-making process.

\section{Ethics}

As aired above, and despite frequent statements generated by scientismprone scholars, economic reasoning cannot be amoral. The notion of right and wrong plays an essential role in shaping human behaviour. More pre- 
cisely, all economic actions refer to how people exploit resources either by making use of widely accepted (legitimate) means, or by violating some behavioural pattern and therefore acting illegally or illegitimately - that is against formal or informal rules, respectively. ${ }^{1}$ Put differently, the shared notion of property rights also defines the borderline between legitimacy and crime. For instance, using violence to cause damage to, or take away resources from, an individual (nuisance and theft, respectively) may be a crime under some circumstances, but may turn out to be acceptable in other situations, say when one of the parties involved is the state.

This is why the economics of property rights is not merely a methodological question, but first of all - and perhaps foremost - a moral issue (see in particular Liggio and Chafuen, Chapter 1). The ethical features of property define its customary origins, and thus to what extent individual or collective properties can be infringed upon and the rights attached to property can be modified. They also explain how property rights evolve. In the end, both the extent to which rights can be claimed and the protection they are awarded become an ideological issue. ${ }^{2}$

Surely, ideology is not enough. Exogenous historical events and technological shocks also play a role, as several chapters in Part III of this volume document at length. But one should not look much further. In particular, one should think twice before accepting in toto the neo-institutional standpoint, whereby property rights are supposed to evolve in some kind of path-dependent fashion, with little hope for individuals and policy makers alike to change the course of events or to see them change through exogenous pressure. Not only would it be a questionable exercise in historicism, therefore with modest explanatory power. ${ }^{3}$ It would also convey the false impression whereby our immediate future depends on built-in, impossible-to-reverse mechanisms inherited from the past. In a nutshell, individual self-responsibility vis-à-vis institutions and institutional change would be seriously weakened. Although the contributions to this volume reflect different moral views, all of them stay clear of the deterministic trap. As Liggio and Chafuen note at the end of their chapter, we are all responsible for the way property rights are going to develop in the future. Changing outcomes by decree is impossible. Efforts in that direction - and ultimately central planning - may lead to tragic results. Instead, our best defence is to identify the role of property rights, and realise that making them subject to discretionary power may have far-reaching and not always well-understood consequences.

\section{Efficiency, externalities and property rights dynamics}

By and large, in the recent past the danger of legal constructivism is gradually being appreciated and the necessity of limiting state intervention recognised. Still, it is also claimed that the pervasive presence of alleged 
market imperfections weakens the case for unconstrained property rights. In other words, transaction costs often prevent their satisfactory specification and enforcement. ${ }^{4}$ True enough, assessing the boundary of property rights always implies some costs, especially if they relate to new goods or services, possibly produced by means of previously unassigned resources. Acquiring the information necessary to exchange property rights (contracts) is also expensive, especially in large communities where contracts are not necessarily the repetition of past transactions concerning the same goods, or carried out by the same people with constant incentive structures. Similar comments apply to property rights enforcement. More generally, it is impossible to avoid that an action carried out by A might actually interfere with B's alleged property rights. And it may also happen that A reduces B's happiness even if no infringement of B's property occurs. Envy is a frequent cause for this. One can imagine many other examples: for instance, competitive action by company A may negatively influence B's profits, or new consumers may compete for the same product and thus provoke a rise in prices, thereby reducing somebody else's surplus (see also Hoppe, Chapter 2).

But the very recurrence of externalities explains why exercises targeted at conceiving the perfect property rights structure tend to be in vain, even if individuals had unlimited abilities to produce, store and elaborate information. Of course, such exercises could also be harmful. Property rights systems should evolve according to the relative value of the resources and goods involved, as well as to the technical possibility of enforcing such rights. At the same time, efforts to develop adequate enforcement technologies are bound to intensify as the expected benefits from enhanced monitoring increase. By looking for perfect arrangements one actually takes for granted what is in fact still unknown. As mentioned earlier, central planning often seems to be an attractive solution; but it is a deadly embrace.

In short, it is certainly justified to point out the range of externalities that are associated with most - if not all - property rights systems originating from spontaneous interaction and voluntary agreement. Many chapters in this volume provide plenty of examples along these lines. Still, one should be very cautious when replacing unconstrained rights of property with alternative regimes, whereby rights are assigned or reassigned at the discretion of some more or less legitimised ruler through top-down processes, allegedly in order to reduce externalities. It can be easily shown that when this happens, new sets of externalities tend to replace the original ones. Moreover, privileges are created and arbitrarily distributed. Indeed, history shows that private interactions and entrepreneurship are generally far more effective in reducing externalities than social engineers designing 'better' or 'fairer' property rights systems. 


\section{An introduction to the Companion}

The questions related to the origin, evolution and effectiveness of economic systems founded on property rights regimes are analysed and assessed in the three parts of this volume. Part I deals with the foundations and thus the legitimacy of property. The boundaries of private property and the extent of legitimate or tolerable interference by policy makers are discussed in detail. Part II is devoted to the analysis of different legal systems from a property rights standpoint and their implications as regards the economics of institutions. Finally, Part III provides some applications of property rights economics to the real world. In particular, it offers a number of important regulatory challenges, and implicitly questions the ambition to achieve static efficiency and 'equitable' distribution, possibly replacing legitimacy with legality.

\section{The origins of property rights}

The first chapter examines the cultural roots of the notion of property and of private property in particular. As Liggio and Chafuen (Chapter 1) document in detail, this idea was already prominent at the dawn of the so-called 'Western civilisation'. Indeed, it had very substantial religious connotations in the Classical world, where private property was sacred because divine ancestors protected it. Violating property was thus equivalent to sacrilege.

But property was by no means a feature limited to the pagans. The authors are extremely persuasive in describing the role of private property both in the Old Testament and in the Christian history of thought as we know it from Saint Paul, Saint Augustine and Aquinas, to name just a few 'giants' of Western thought. As for the future, Liggio and Chafuen observe that attacks have been frequent over the centuries and on both sides of the Atlantic. Until recently these were successfully resisted because - the authors conclude morality was dominated by deep individual religious awareness and commitments. The strength and quality of such ethical commitments will thus shape the reaction to the current and forthcoming threats.

Hoppe (Chapter 2) develops the discussion of the moral element in a private property rights system, and argues that unconstrained property represents the only feasible solution to the problem of social order in a world of scarcity. Contrary to what is usually claimed, a world without property rights would not only be one without much peaceful interaction (the problem of social order in its traditional form), but also one where individual behaviour would not be legitimate. For human behaviour can only take place if actors own their body and have a claim on the space they are occupying to start with. This and the Pareto optimality criterion for social welfare justify the rule of 'originally appropriated places and goods'. This means that one may appropriate resources (i) if they have not been previously appropriated by 
others, which also implies that B cannot be hurt by A's appropriation, otherwise $\mathrm{B}$ would have established his/her property rights before A; and (ii) if the owner to be demonstrates that these resources are enhanced by his/her own work. ${ }^{5}$ In all other cases resources can be appropriated only through voluntary exchange, otherwise it would be a violation of somebody's established property rights, that is, a violation of the basic rule of social order.

By calling upon the history of Western thought extending from Locke (at least) to Rothbard, Hoppe shows that there are only two alternatives to action and interaction based on property rights. One is an unequal world populated by Uebermenschen (who decide and are allowed to act) and Untermenschen (who take orders and have to ask permission for whatever they do). In other words, one should assume that not all men have equal dignity. The other alternative is 'universal communism', which is of course unfeasible, for everybody should ask permission from all other individuals (including those yet to be born), lest externalities are created.

Although the moral foundations of property rights were clearly perceived both in the Classical world (Aristotle and then the Roman legal tradition) and in the Western (Christian) civilisation, according to Hoppe such principles have been substantially weakened in recent times, as economics became increasingly involved with providing answers to political needs, while political philosophy tried to provide new alibis to policy makers. Sometimes these efforts were transparent. Sometimes they were the indirect results of wellmeaning research programmes. Among the latter, during the past decades several Chicago scholars deserve credit for having drawn attention to the property rights problem from the standpoint of economic efficiency. But this should not conceal the fact that these authors ended up by denying the moral dimension of economics and allowed the initial property rights assignment to be overruled following the onset of a technological environment. Hence, the apparent legitimacy of technocratic conjectures, of cost-benefit analyses based on social utility maximisation, and of the gradual transformation of property rights into a matter of technocratic discretion.

Parisi (Chapter 3) does not deny the moral dimension of property rights structures, but tends to devote more attention to their dynamics as a pathdependent process, hopefully with a happy end. In particular he observes that as a result of demographic pressure and/or new social organisations - the family replacing the clan - collective-property systems gradually weakened. Private rights proved to be an effective response to the scarcity problem as they enhanced a more efficient use of increasingly scarce resources. Similar remarks apply to the notion of absolute ownership, introduced within the context of Roman law and further enhanced after the feudal period. Indeed, after the French Revolution, legislators enforced such principles even against the will of the parties. However, the tensions that followed ultimately led to 
more freedom of contract in the twentieth century, in both civil and common law jurisdictions.

There is no doubt that property rights are the key to economic growth and enhanced well-being. Nevertheless, Parisi's conclusions are not warranted. Today much of the world's population live in societies where property rights are badly specified and poorly enforced. Indeed, property rights have failed to evolve in desirable ways. One needs to clarify why.

The contributions by Norton (Chapter 4) and Libecap (Chapter 5) offer two different but mutually compatible accounts. On the one hand, Norton calls the readers' attention to cultural elements. After carefully reviewing the debate on the role of culture as an explanatory variable for aggregate economic performance, he focuses on the link between culture and institutions, the former being understood as a 'system of values and beliefs'. In particular, by examining data over the 1982-95 period, Norton finds that only individualism is strongly correlated with a satisfactory property rights system, while ethnic homogeneity, religion and path dependence seem to be playing a minor role. He concludes that since ethical systems are hard to transmit and absorb in the short run, relatively quick, top-down transfers of successful institutional systems to relatively poor countries are virtually impossible.

On the other hand, Libecap underscores transaction costs as the major impediment to moving from one property rights system to another. For instance, lack of information prevents economic actors from appreciating the benefits of institutional change, collective-action problems make negotiations difficult, while some actors - including politicians - decline to consider a more efficient distribution of rights if it would jeopardise their rents (privileges) and powers. In all these cases, institutional change slows down or stands still. Two historical examples persuasively document the nature and magnitude of such barriers to change: the American Great Plains in the late nineteenth and early twentieth centuries, when the climate changed significantly, and the reallocation of water rights in semi-arid western US states. In the former case, efficiency would have required larger plots, but politicians opposed the concentration of property fearing migration out of the region and thus a smaller electorate, which in turn would have diluted political power at the federal level. Of course, compensation for these lost rents could not be proposed for lack of moral legitimacy. Thus, when crisis struck, subsidies were preferred to superior institutional solutions, which would have allowed faster farm consolidation and the adoption of better farming technologies.

The second example illustrates the difficulties met in reallocating water from relatively inefficient agricultural to more desirable urban uses. In particular, rights could not be transferred due to high negotiation costs (heterogeneous and fragmented owners or jurisdictions) and inadequate information. Legislative efforts to provide top-down rules of the game - 
sometimes also driven by equity concerns and electoral interests - added further ambiguities and uncertainty.

\section{Property rights and the law}

All the contributions presented in Part I maintain that property rights are a fundamental condition for growth. But that condition is not sufficient when the moral foundations of property are undermined, or transaction costs are kept too high for beneficial evolution to occur. Having this framework in mind, Part II offers the basic elements for understanding how and to what extent policy makers (including the judiciary) try to influence and/or create property rights structures.

At one extreme, Barrère (Chapter 6) discusses the notion of legal efficiency by assigning the judiciary the role of an Uebermensch, in Hoppe's terminology. From a different perspective, Voigt (Chapter 7) and Barry (Chapter 8) deal with the issues raised by the comparison of different legal regimes. Finally, Rapaczynski (Chapter 9) and Cass (Chapter 10) evaluate whether an effective property rights system does require constitutional protection against possible attacks by populist policy making, so as to provide and enforce the rule of law.

Barrère does not deny that a clear assignment of property rights and a strict and often formalised system of sanctions is required to obtain economic growth. He nevertheless believes that the policy maker and the judge have a moral duty to exercise discretion for two sets of reasons: first, in order to lower transaction costs (contracts can never be complete), and accelerate trial-and-error processes within a 'Hayekian' society; and second, he claims that since all legal approaches to property necessarily affect individual wellbeing, the judge has a duty to conceive and enforce viable compromises when property rights are not assigned fairly or clearly enough. In other words, whenever the market process is supposed to need help.

Voigt is less enthusiastic about top-down solutions by more or less omniscient policy makers that know what is best (or will be best) for society. Indeed, in his view the very fact that different groups may prefer different sets of rules is a powerful source of potential conflict. ${ }^{6}$ This happens, for instance, as a consequence of historical and political accidents (political unification through the rise of the nation-state, colonisation, or transition from communism), so that the rules of a new regime partially or totally supplant those typical of the previous one. It can also occur in heterogeneous societies, where different groups try to promote their own interests, possibly at the expense of others.

Voigt argues that under such circumstances the persistence of unofficial systems remains pervasive, as witnessed by the existence of large underground activities, including corruption. The cost of having one or more 
systems using violence to suppress rival arrangements may be considerable, since individuals choosing one system must suffer the cost of escaping sanctions from the others. Hence, there is a risk that more resources will be spent by each of the various authorities to enforce their own preferences. ${ }^{7}$

Since the legal present of a country depends on its legal history (path dependence), according to Voigt there is little one can do to make sure that relatively peaceful competition prevails upon violent conflict, unless legal transplants are attempted, and new path-dependent processes set in motion. Still, the author aptly raises a number of doubts about the possibility of transferring property rights systems from one country to another. Perhaps transfers de iure are technically feasible. But of course, history demonstrates that enforcing procedures is not enough to warrant success, and that topdown attempts to introduce supranational legislation may be part of the problem, rather than of the solution.

Indeed, it is not even quite clear what kind of system should be transferred for the sake of efficiency. For instance, the alleged superiority of the common law system cannot be taken for granted. Barry strengthens and deepens Voigt's insights on this.

In particular, Barry's chapter compares procedures under the civil and common law systems. The former presents itself as a set of rules originally rooted in fundamental principles (natural order), to which rules and regulations - and also different court systems - have been added in order to accommodate new needs. On the other hand, the common law system is based on precedent (past experience being a guide to the actual will of the contracting parties), with the judge in charge of finding out the relevant precedent and of applying it. By not being anchored to a system of fundamental principles, but rather to a criterion of 'acceptable behaviour', the common law system is thought to be simpler, more flexible, open to innovative decisions and more conducive to voluntary agreements between the parties involved. That is why common law is usually thought to be closer to the needs of a modern market economy.

Despite apparently serious diversities, however, Barry claims that neither system has in fact been able to resist pressure towards regulation. That is, although significant differences remain, for instance when assessing property rights in the presence of externalities, both standards have been suffering from political influence, special interest groups and government intervention. Similarly, takings with compensation seems to be the prevailing utilitarian solution under both legal systems, even if that is an obvious breach of property rights principles and even when state authorities are not involved. In other words, Barry sees the divergence between common and civil law systems become increasingly narrow as a consequence of state intervention. It is therefore hard to claim that one system is better than others at protecting 
property rights. More relevant alternatives are perhaps to be found in constitutions, some of which may well be more effective than others.

In this respect both Rapaczynski and Cass have doubts, though. In particular, Rapaczynski reviews some key elements of constitutional theory: the so-called "personality theory" ${ }^{\prime}$ is too vague to justify the very existence of property rights, let alone warrant constitutional protection. Protecting and enforcing property rights in order to support political freedom and ultimately assert the notion of citizenship is a more persuasive argument. If so, can one then claim that constitutions are a suitable device to enhance such protection and enforcement?

Rapaczynski does not think so. He maintains that constitutions are not designed to protect unrestrained economic freedom. Thus, they should not be used to that purpose. For example, the American experience proves that constitutional law making has been far more successful at shielding basic political freedom than at stopping political interference (including regulation) in private economic activities. According to the author's viewpoint, however, this may not necessarily be undesirable, for constitutions should always be subdued to the principles of democratic rule. As a matter of fact, by adopting a rather cautious attitude vis-à-vis classical and radical liberalism he argues that constitutions do not and should not protect wealth creation in the face of democratic policy making, especially when redistribution of wealth is in order. Furthermore, there are other good reasons not to provide unconditional protection (including full compensation for takings) to private property rights, for instance, when some private rights are harmful to what Rapaczynski identifies as 'social efficiency'.

Other tools may be more suitable in preserving private property rights, if and when it is appropriate to do so. To this purpose, Rapaczynski favours the adoption of schemes that make the goals and outcomes of policy action more transparent, and suggests that private property rights can indeed be legitimately weakened or simply violated if that enhances social efficiency. This is why well-designed and easily understandable evaluation procedures - perhaps subject to frequent electoral tests - are to be preferred to the rigidities of a constitutional norm.

On the other hand, Cass considers that the features of societies that deviate from the rule of law - including the right to engage in voluntary contracts are weak. Similarly to Rapaczynski, Cass does not deny that property rights systems are subject to change and evolution. Contrary to the previous author, however, Cass concentrates on how change comes about and on how effectively discretionary power is constrained, which is the very purpose of constitutional safeguards. Indeed, Cass posits that legal systems and economic performances differ across countries as a consequence of the quality of the constraints imposed upon official discretionary powers. For instance, 
Western democracies have been far more successful in limiting arbitrary violations of property rights than autocracies in other parts of the world.

In this light, Cass observes that the ability of a system to limit discretion is not necessarily embedded in the formal rules (constitutions). To clarify this point, the author compares the cases of Zimbabwe and the United States. In the former country, constitutions did establish sets of rules, but the ruling élites never found substantial difficulties in changing the constitution at will. As a consequence, the law was not broken, since constitutional principles could be amended legally, despite occasional opposition by the Supreme Court. But rule of law was of course shattered.

On the contrary, US procedures can do much more to protect property, mainly thanks to the system of checks and balances among the different jurisdictions, which is a typical feature of the American structure of power. As a result, changing the law becomes a slow and often difficult affair. It adds certainty and stability to the rules of the game.

The last part of the chapter discusses whether there can be desirable exceptions to the rule of law, that is, whether discretion is to be allowed under given circumstances. Cass's answer is positive, as long as individuals can take decisions in a predictable enough environment. As a matter of fact, he believes that predictability turns out to be a better principle than discretion when evaluating the quality of a property rights system and the legitimacy of changes imposed by the authorities. Discretion is necessary whenever the norm has some degree of generality - which is inevitable, since the legislator cannot be omniscient and monitoring costs are far from zero. From this standpoint, therefore, the difference between Zimbabwe and the United States is not discretion per se, but the fact that while discretion is constrained by cross-checks in the United States, it is virtually unbridled in Mugabe's regime.

\section{Property rights economics in action}

Most of the theoretical problems raised in Part II reveal their implications when property rights principles are applied to real life. Some authors seem to be closer to the views held by Hoppe and Norton, who argue that property rights are rooted in the natural order and therefore can never be violated. When such natural rights are tampered with, following cultural and ideological fashions, economic performance will suffer. Most efforts should thus be devoted to enhancing the definition and enforcement of property rights hopefully in a cultural environment favourable to private property rights structures. On the other hand, some scholars are more inclined to allow weakened property rights systems so as to overcome unquestionable inefficiencies provoked - mainly - by collective-action problems. Part III of the Companion is devoted to these differences. 
Colombatto (Chapter 11) belongs to the first group. He draws attention to the cultural traits of a society - morality once again - in order to cast doubts upon the recent literature on development economics, which has moved from neoclassical policy making, towards institutional constructivism, and now advocates the creation of allegedly suitable property rights structures to promote growth in poor countries. The author claims that the enforcement of property rights is surely crucial for development, but that it is a mistake to believe that property rights can be used as a tool for policy making and social engineering, following the latest Western tradition and experience of weakening private property. By doing so, Western developed countries have actually undermined the case for a social order based on self-responsibility. Entrepreneurship has been discouraged and the opportunities for growth have been further cut back. In short, it is hard to see how the poor can improve their well-being by referring to a moral system that keeps undermining self-responsibility and entrepreneurship.

Cohen (Chapter 12) also refers to the moral foundations of property rights in order to develop a set of powerful arguments to justify human genes manipulation (germline engineering). He substantiates his claim by referring to (i) the little disputed property right of each individual over his/her own body; a right that can be legitimately violated only when individuals pose a serious threat to other human beings. Furthermore, he recalls that (ii) in our civilisation parents can legitimately decide on behalf of their children - or of their unborn children - until their offspring can express their preferences and be aware of the possible consequences. Surely, if parents are assumed to act in the interest of their offspring outside the domain of germline engineering, then there is no reason to believe that they would change their attitude once genetic manipulation is admitted. Consistent with the free-market tradition, Cohen does not claim that parents always make the best possible choices. Nobody is perfect. But he does not believe that on average a bureaucrat or a policy maker can do better when deciding on behalf of somebody else's children.

There is no doubt that germline engineering may be a source of externalities. Most human choices are, as mentioned earlier. But as long as human action does not use violence in order to inhibit other people's choice or to reduce the right to enjoy property, ${ }^{9}$ one has no right to restrain behaviour. This is again a moral problem which, however, leads to dynamic efficiency. The history of humankind shows that extensive choice and non-violent competition for scarce resources have been crucial in reducing rents and enhancing progress; even if gains have seldom been spread evenly across the population. ${ }^{10}$

In the chapters that follow, the focus shifts from the moral implications of property rights economics to the problems due to scarcity and externalities, 
the latter being interpreted as the failure to develop a suitable set of contracts. Consistent with this view, Anderson and McCormick (Chapter 13) concentrate on the environment and the so-called divergences between private and social outcomes, which is in fact another way of describing the problem of conflicting uses for a scarce resource when property rights are not well defined. In particular they apply Coase's seminal idea on the nature of the firm, whereby previously abundant resources are transformed into valuable assets through contracts, thereby specifying (transferable) property rights and eliminating the tragedy of the commons. Thus, the chapter argues that entrepreneurship in an environmental context consists of the ability to perceive scarcity before others do, and find ways to overcome contracting costs.

Of course, Anderson and McCormick do not belittle the cost of monitoring and transferring property rights. Still, although voluntary exchange through compensation is not always legally necessary, potential regulators should bear in mind that top-down directives often lead to resistance and thus to inefficiency. This is indeed similar to what happens in the firm, where motivation - rewards and penalties for good and bad decisions and appropriate reactions to new information - works better than simple rule making. In short, Anderson and McCormick claim that the celebrated problem of externalities is not an issue, but the consequence of an entrepreneurial failure to reduce transaction costs and develop suitable contractual arrangements. Hence, more efforts should be devoted to enhancing entrepreneurship as a way to solve scarcities in environmental goods, rather than taking externalities for granted and designing optimal policies to regulate and constrain economic activities.

The vulnerability of property rights economics vis-à-vis regulation is the subject of Lee's contribution (Chapter 14), where it is maintained that the crucial role of property rights and voluntary exchange within a market system is seldom perceived, let alone acknowledged. This is due to ignorance, avarice and envy, as well to the dispersion of benefits and the concentration of costs. Similarly, it is also overlooked that when property rights are not defined, enforced and exchanged, individuals are no longer responsible for their actions. Hence, freedom is more likely to be violated. Not surprisingly, regulation and coercion tend to be the suggested solutions to redress alleged unfairness and obtain political consensus, ${ }^{11}$ not freedom. To make his point, Lee recalls the essence of the public choice literature, which emphasises the high cost the general public incur to acquire information about the damages generated by coercive policies; while the beneficiaries need little encouragement to perceive the gains from rent seeking and forcefully engage in rhetoric exercises to persuade public opinion.

The remaining part of his contribution provides three fitting examples. One discusses the case of mandatory benefits for employees, to be provided by 
their employers. Such benefits are generally perceived as a protection for the worker, whereas they are in fact equivalent to forcing workers to buy services they are not willing to buy (otherwise no compulsion would be necessary). More important, Lee shows that the true beneficiaries are indeed the inefficient producers, who try to raise costs for their competitors, and the workers' cartels, which aim at raising entry barriers for low-cost (unskilled) labour.

The second example focuses on the restrictions imposed on hostile takeovers. Economics has made clear that hostile takeovers are the most powerful way to restrain potential misbehaviour by incumbent managers. Misconduct would reduce the value of the shares, make the company vulnerable to a takeover by new owners who then replace at least part of the management. In other words, hostile takeovers are good for stockowners, and harmful for bad managers. Not surprisingly, the latter are most active in mobilising public opinion so as to raise the cost of hostile takeovers and - more generally restrain competition. While they claim they are fighting to avoid shutdowns and losses of employment, they are in fact protecting their own jobs against the public interest.

Along similar lines, the case for global warming shows that the major beneficiaries from the regulatory policies to reduce temperatures is not the world population, but the huge bureaucracies that would be created to run these world-scale programmes. Frightening the population in order to justify such programmes is of course part of the game.

Two among Lee's insights are further developed in the next two chapters. Benson and McChesney (Chapter 15) devote their attention to corruption: an important aspect of bureaucratic organisations and - more generally - of societies where regulation has replaced property rights. Garello (Chapter 16), on the other hand, examines the domain of corporate governance.

In a nutshell, Benson and McChesney follow Lee's approach in that they consider the regulatory solution generates an adequate property rights regime, and discover that corruption in the public sector is the byproduct of such a solution. The economic profession usually regards corruption as something morally deplorable and a source of deadweight losses. On the other hand, according to Benson and McChesney, public corruption originates from the property rights attributed to government officials, so that bureaucrats and politicians end up by enjoying considerable coercive power - for instance, as regards taxation - but are hardly accountable for their conduct. This explains corrupt behaviour not only under the form of embezzlement, but also - and more appropriately - when officials are bribed not to enforce the law, to pass or not to pass legislation (rent seeking and rent extraction, respectively).

This is why corruption can be conceived as a form of payment to the policy maker in order to reduce his/her discretionary power. And discretionary or regulatory power is of course a matter of property rights. In the end, the 
economics of property rights helps once more to clarify that regulation is part of the problem, rather than of the solution. Hence, as the authors argue at great length, little can be expected from the efforts to stamp out corruption unless one radically changes the institutional framework (that is, property rights assignments).

Within the areas of shareholders' and managers' behaviour, and similarly to Lee, Garello attributes the ease with which regulation is enforced to ignorance as regards the origins of the modern corporate firm and of limited liability in particular. Limited liability emerged as a contractual arrangement designed to raise large amounts of capital when owners' control necessarily becomes weaker. As a result, exit costs for the owner are reduced and part of the risk is shifted to lenders. Two cases are illustrated to clarify the point: legislation on insider trading and on takeovers.

Indeed, by regulating 'insider trading' in order to make sure that owners have equal access to information means that one has not really understood the role of the owners in a limited-liability company. Under such circumstances, shareholders have explicitly decided not to incur the cost of acquiring all the information necessary to strictly monitor how the company operates. In other words, regulating insider trading cannot be explained by the need to protect a property right on information - and thus on potential profits - held by the shareholders, for the shareholders of a limited liability company clearly chose not to gather information. Surely, if deemed desirable, shareholders may decide to force managers to abstain from trading company shares. ${ }^{12}$ But of course, that is just a voluntary contract among the majority of shareholders, with no need for outside (state) regulation.

Legislation against takeovers is also the result of ignorance, for takeovers usually benefit the shareholders of the target company without harming the buyer. Indeed, it is a situation whereby outsiders take care of the monitoring that shareholders find too expensive to carry out themselves. Once again, this is revealed by the very essence of a limited liability contract.

Garello thus concludes that in both cases - insider trading and takeovers the true beneficiaries from regulatory legislation are not the shareholders, but rather easy to identify pressure groups. Support for normative intervention will then be found among professional providers of information when it comes to insider trading, rent-seeking managers when it comes to hostile takeovers, and all those who have an interest in stopping competitors from becoming stronger when it comes to mergers (including those accomplished by means of friendly takeovers). In addition, one should not forget the role of alleged regulatory experts and bureaucrats looking for more discretionary power and larger budgets. In the end, by reducing property rights and suffocating competition in the area of corporate governance one actually harms the interests of the weaker parties. 
Garrouste (Chapter 17) also deals with the theory of the firm and contrasts the traditional view, which holds that property rights are instrumental in internalising externalities in production, with the new approach, whereby the firm remains a more or less centralised ownership structure issuing instructions aimed at maximising the owner's target. Decentralised decision making is relegated to areas where uncertainty and incomplete contracts prevail. Such recent theories raise a number of questions about the desirability of voluntary contracts. Nevertheless, although Garrouste credits these new theories with drawing attention to a number of relatively new issues, he believes that at present normative intervention to enhance efficiency is still far from justified.

The remaining chapters of the book focus on intellectual property rights. Isaac and Park (Chapter 18) discuss the foundations of such rights and suggest a free and open system solution (no protection for property). Antonelli (Chapter 19) and Brousseau (Chapter 20) examine the positive and normative economics of knowledge from a neoclassical standpoint, leading to ad hoc solutions elaborated by regulatory bodies. Cuccia and Santagata (Chapter 21) provide a case study describing the problems met when designing suitable collective 'cultural' property rights. Finally, Amacher and Meiners (Chapter 22) look at a different sort of intellectual capital - education.

Isaac and Park address the economics of the most important set of property rights to protect inventions - patents. The traditional view is well known. On the one hand, patents encourage technological progress by offering at least temporary monopoly power on the result of innovation (rather than on abstract ideas, which are not patentable). On the other, they often create barriers to entry for other innovators, who are prevented from developing new products starting from somebody else's discoveries. As a result, Isaac and Park caution against property rights to pure or 'near' ideas. In their view pure ideas or near ideas should remain unpatentable, promoting freedom to innovate by making use of other's ideas.

After reviewing the principles and the considerable ambiguities characterising the existing legislation on patents - say, in the software industry Isaac and Park show how a free and open system enhances the use of the existing technologies, but does not necessarily discourage innovation. This occurs not only when innovators carry out research and development (R\&D) with relatively little concern for monetary rewards but also when free and open development proves complimentary to other profitable activities. In other words, according to Isaac and Park, patents promote market power and thus entail static social costs, but they are not guaranteed to provide offsetting dynamic gains. On the contrary, the development of free technology may offer new opportunities for monetary profits to a large number of companies, which may in turn further promote the use of existing knowhow and also create new technologies. 
Still, Isaac and Park conclude that free and open systems are not inevitably in conflict with proprietary systems, unless innovators following one of the two approaches can prevent others from carrying out their own innovation which is more than just a theoretical possibility. Indeed, the assessment of the interaction between these two systems remains open and in many respects elusive.

Antonelli's work analyses the economic nature of knowledge in greater depth. In particular, since knowledge is the outcome of a learning process that takes place almost exclusively within the firm, production functions are no longer viewed as well-known blueprints more or less accessible to all managers. Instead, they become highly dependent on the learning path typical of each firm. Hence, they are firm specific, appropriable and tradable. From this standpoint, Antonelli maintains that the market for knowledge is not much different from any other market, and that property rights economics should apply to the production and trade of knowledge, too. In particular, different property rights features as regards their definition, assignment and exclusivity affect the way firms behave: make-or-buy and make-or-sell choices on the one hand, selecting different patterns of integration on the other. In short, knowledge is no public good. Thus, and contrary to what is argued by much of the literature following the Arrow tradition until some two decades ago, subsidies, public procurement and state ownership in key R\&D industries can no longer be regarded as the basic instruments to enhance technological progress.

Although Antonelli is aware of the fact that the enforcement of private property rights enhances the production of knowledge, he does not overlook the possibility that such rights might lead to externalities, for by creating monopoly power the diffusion of knowledge is reduced and progress retarded. This is actually the core of the economics of patents, as mentioned in the previous chapters of the Companion. By referring the reader to the set of cases known as 'essential facilities' within telecommunication networks, Antonelli concludes that property rights on knowledge - which includes the whole area of intellectual property rights - should thus be weakened by regulation, and (neoclassical) competition enhanced. One example along such lines is compulsory licensing at 'fair prices', to be decided by the judiciary ex post, that is, after the new knowledge has been created.

Brousseau also focuses on an area - digital technologies - where marginal costs of production are low and the case for a revival of the economics of public goods seems to be stronger. In particular, Brousseau argues that in this area a fully decentralised property rights system would not be desirable. Hence, his argument for the establishment of a central authority with the responsibility of fixing and monitoring the rules of the game. In other words, a central authority would establish and - if necessary - assign property 
rights. Although the author is aware of the costs involved, he believes that in the case of the Internet the advantages of a centralised solution in terms of fairness, better management of addressing systems, economies of scale, economies of scope and cumulative learning processes would prevail.

Another set of situations that are still looking for suitable property rights solutions is analysed by Cuccia and Santagata. They observe what happens when the demand for a precise definition and assignment of intellectual property rights intensifies in a so-called 'cultural district'. ${ }^{13}$ After a detailed description of the origins of a typical cultural district (Caltagirone, Sicily), and of the way its production results from specific historical and geographical traits, the chapter explains how a collective trade mark characterising culture-intensive goods may be an effective way to enhance market power, reduce transaction costs and keep out low-quality free riders. However, the authors discover that although producers do acknowledge the need for protection against counterfeiting and free riding, cooperation is viewed with scepticism and the creation of a collective trademark seems not to be particularly welcome. Craftsmen definitely prefer to sign their products individually, piece by piece, and little importance is attributed to the fact that most of the reputation is linked to the district, rather than to the creator. Cuccia and Santagata analyse this behaviour by means of a game-theory exercise, whereby it is shown that a collective trademark is acceptable only if it is designed to convey information about the geographical origin, while remaining clearly distinct from quality certification. But since geographical origin is attributed little importance, all attempts to create and enforce property rights on the cultural district are likely to be in vain.

The final chapter of the volume suggests that fine-tuning collective property rights in the areas of culture and intellectual property may well rank among the great challenges for the years to come. As Amacher and Meiners show, the domain of higher education is a clear example of a situation where transaction costs and perverted incentive structures make it difficult for a residual claimant to emerge. Therefore, making a profit or suffering a loss make little difference. Governing bodies end up by minimising tensions and drastic changes. The solution of controversial problems tends to be postponed, compromises are usually looked for, accepted and justified through 'democratic' procedures. Lack of clear property rights is once again the origin of waste.

\section{Notes}

1. Formal rules emanate from a legislative authority through a top-down procedure, whereas informal rules - culture, traditions, customs - are the product of a slow bottom-up process elaborated by a community through repeated interaction.

2. That is, if one believes that ideology shapes moral standards.

3. The so-called 'historical school' and its modern versions argue that economists should be 
concerned with little beyond fact collection and more or less sophisticated quantitative analyses, with no ambition to explain complex phenomena. This approach is now by and large discredited. Most would agree that the major concern of the economics profession should be understanding and sometimes influencing the behaviour of individuals in a context characterised by scarce resources.

4. In order to claim perfect knowledge one should have a theory about the end of human scarcity or about the end of humankind's desires to improve their condition, while in order to protect property rights perfectly, one should assume zero transaction costs.

5. This is the first-user-first-owner rule that Hoppe refers to. For instance, it explains why the Spanish Crown's claims to hold property rights over the whole New World as from 1492 were meaningless. The Spaniards were not the first users (other people were there), and were not using most of the territory they were claiming.

6. Of course, systems can also compete, rather than clash. However, Voigt agrees with Harold Berman in saying that this is not very realistic in today's political environments, which seem more prone to centralisation and/or transnational harmonisation, and less favourable to institutional competition.

7. But the author also recalls Berman's work, which showed that situations characterised by competing systems lead to growth, as the history of the Western world has shown.

8. According to the personality theory, property rights are instrumental in allowing the individual to develop and complete his/her personality, for by appropriating a commodity people are able to expand and develop their own traits.

9. Of course, the right to enjoy property (which is morally justified) differs from the desire not to see the value of property fall (which justifies no protection). Theft belongs to the first category; while physical or technological decay belongs to the second.

10. When it comes to germline engineering, Cohen notices that, except in truly exceptional circumstances, everybody is a winner, and the poor probably more so than the rich.

11. Contrary to the functioning of the market process, political action concentrates the benefits and disperses the costs. Although these are usually much larger than the benefits, the benefits become clearly discernible, while the costs tend to go unnoticed.

12. That is equivalent to claiming a property right on the information created within the company, and at the same time to preventing managers or specific shareholders (for example, board members) to make use of such information by disseminating it.

13. A cultural district is defined as an area featuring a unique cultural heritage that translates into entrepreneurship and manufacturing with distinctive elements originating from that local culture. According to Cuccia and Santagata, and contrary to what can be observed in industrial districts, economic development in cultural districts depends heavily on the collective exploitation of the intangible assets derived from the common cultural heritage. Hence the potential need to protect collective property rights. 